Review Article

\title{
Different Therapeutic Effects of Transcranial Direct Current Stimulation on Upper and Lower Limb Recovery of Stroke Patients with Motor Dysfunction: A Meta-Analysis
}

\author{
Xi Bai, ${ }^{1}$ Zhiwei Guo $\mathbb{D}^{1},{ }^{1}$ Lin He, ${ }^{1}$ Long Ren, ${ }^{2}$ Morgan A. McClure, ${ }^{1}$ and Qiwen Mu $\mathbb{D}^{1,3}$ \\ ${ }^{1}$ Department of Radiology and Imaging Institute of Rehabilitation and Development of Brain Function, The Second Clinical Medical \\ College of North Sichuan Medical College Nanchong Central Hospital, Nanchong, China \\ ${ }^{2}$ Department of Radiology, The Fifth People's Hospital of Nanchong, Nanchong, China \\ ${ }^{3}$ Department of Radiology, Peking University Third Hospital, Beijing, China
}

Correspondence should be addressed to Qiwen Mu; muqiwen99@yahoo.com

Xi Bai and Zhiwei Guo contributed equally to this work.

Received 8 July 2019; Accepted 9 October 2019; Published 16 November 2019

Academic Editor: Paolo Girlanda

Copyright (C) 2019 Xi Bai et al. This is an open access article distributed under the Creative Commons Attribution License, which permits unrestricted use, distribution, and reproduction in any medium, provided the original work is properly cited.

Objective. To explore the effects of transcranial direct current stimulation (tDCS) on the motor recovery of stroke patients and the effect differences between the upper limb and lower limb. Methods. Randomized control trials published until January 2019 were searched from PubMed, Embase, ScienceDirect, and Cochrane Library databases. The standardized mean difference (SMD) with 95\% confidence interval (CI) was estimated separately for upper and lower limb motor outcomes to understand the mean effect size. Results. Twenty-nine studies with 664 subjects were included in this meta-analysis. The overall analyses of tDCS demonstrated significant effect size both for the upper limb (SMD $=0.26, P=0.002)$ and the lower limb $(S M D=0.47, P=0.002)$. Compared with acute and subacute stroke patients, chronic stroke patients obtained significant effects after $\mathrm{tDCS}(\mathrm{SMD}=0.25$, $P=0.03$ ) in upper limb function. Furthermore, both anode and cathode stimulations produced significant effect size for stroke patients after $\leq 10$ sessions of tDCS (anode: $\mathrm{SMD}=0.40, P=0.001$; cathode: $\mathrm{SMD}=0.79, P<0.0001$ ) with $>0.029 \mathrm{~mA} / \mathrm{cm}^{2}$ of density (anode: $\mathrm{SMD}=0.46, P=0.002$; cathode: $\mathrm{SMD}=0.79, P<0.0001$ ). But for lower limb function, more prominent effects were found in subacute stroke patients $(\mathrm{SMD}=0.56, P=0.001)$ with bilateral $\mathrm{tDCS}(\mathrm{SMD}=0.59, p=0.009)$. Conclusion. $\mathrm{tDCS}$ is effective for the recovery of stroke patients with motor dysfunction. In addition, upper limb and lower limb functions obtain distinct effects from different therapeutic parameters of tDCS at different stages, respectively.

\section{Introduction}

Stroke, a kind of cerebral blood circulation disorder disease which can cause neurological deficits, is one of the leading causes of disability in the world's elderly population [1]. Studies have predicted that stroke will occupy an undeniable proportion of the global burden of disease by 2020 reaching to $6.2 \%$ [2]. It is, therefore, very necessary to find a useful way to recover the motor function of paretic limb after stroke. The interhemispheric competition mechanism shows a reciprocal inhibition of the neural activity between bilateral hemispheres in a healthy brain, which is realized by the transcallosal fibers [3]. The balance is broken after a unilateral stroke resulting in excessive excitation of the unaffected hemisphere and increased inhibition to the affected hemisphere [4]. Therefore, rebalance of the brain is the key for the recovery of function [5]. In addition to competition mechanism, a recent, bimodal balance-recovery model has been proposed which holds that the competition and vicariation model combined to regulate the balance between the hemispheres [6].

Conventional therapies including constraint-induced movement therapy $[7,8]$, robotic training [9], and occupational therapy [10] play an important role for the recovery 


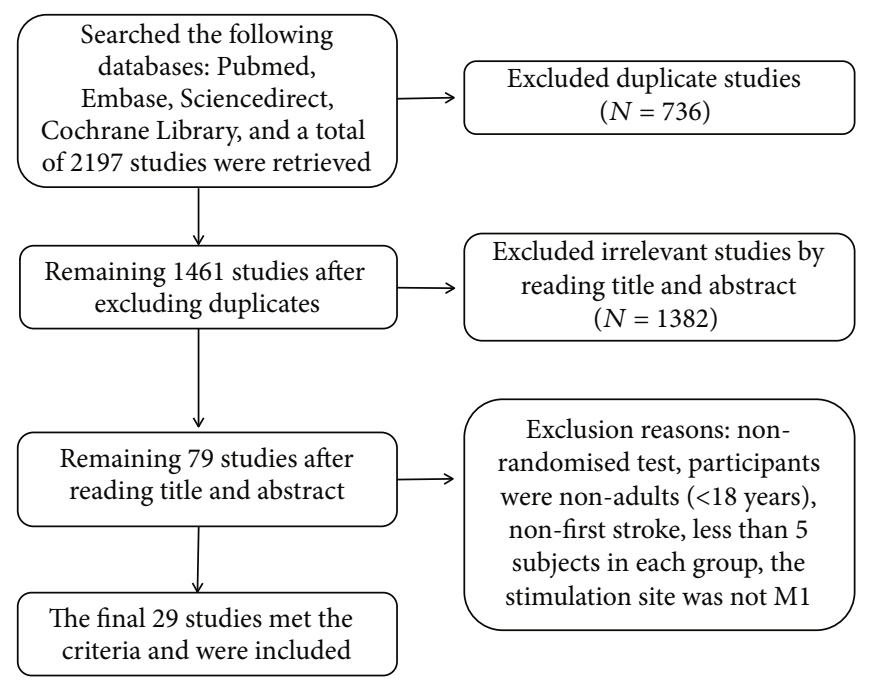

FIgURE 1: The specific flow chart of selection process.

of motor function after stroke, but these physiotherapies have some limitations which make researchers intend to seek more effective ways to boost limb function recovery by reinforcing cortical plasticity [6]. Noninvasive brain stimulation has been prevalent in recent years. These mainly include tDCS and repetitive transcranial magnetic stimulation (rTMS). Compared with rTMS and traditional treatment methods, tDCS has the characteristics of feasibility, costeffectiveness, convenience, etc. Also, a review [11] and two meta-analyses $[12,13]$ have indicated that tDCS is safe and tolerable. Up to now, a large number of studies on tDCS applied to neurological diseases have been published, such as stroke [14], depression [15, 16], and Parkinson's disease [17]. Noninvasive tDCS regulates motor cortex excitability mainly by influencing the polarity of the membrane [18]. Anode increases excitability and cathode reduces excitability [19]. Therefore, when the anode is applied to the ipsilesional cerebral hemisphere or the cathode to the contralesional hemisphere, the balance between the interhemispheres could be restored. Someone had described that cortical electrical stimulation combined with a motor training was better in improving motor function of the affected hand than a motor training alone [20]. And early intervention reduces the likelihood of functional disability [21].

Several reviews and meta-analyses had previously investigated the recovery of tDCS to upper limb motor function in survivors of stroke [20, 22-25]. However, opinions were varied. The majority of researches showed a beneficial effect to a paretic upper limb in stroke patients by tDCS [20,24, 25], but in another two studies, one showed a tiny, nonsignificant effect on the impairment of upper extremity [22], and the other indicated that tDCS had no effect on the recovery of the arm function [23]. It was precisely because of the disagreements that further exploration was required. Furthermore, few articles discuss the specific parameters of tDCS to the upper limb. We would explore these in this article. Before our study, few reviews had researched the effect of tDCS on the lower limb function. Only one meta-analysis denoted that tDCS improved the lower limb muscle strength
[26]. It is valuable to do something in lower limb function after stroke.

To sum up, the main purpose of this meta-analysis was to obtain different therapeutic effects of tDCS on upper and lower limb recovery of stroke patients with motor dysfunction. First, we need to confirm whether tDCS is beneficial to upper and lower limb function after first unilateral stroke and then to further explore the optimal parameters of tDCS and which stage of stroke is more effective by tDCS.

\section{Methods}

2.1. Search Strategy. We have searched clinical trials published before January 12, 2019, from PubMed, Embase, ScienceDirect, and Cochrane Library databases. The keywords were "tDCS" or "transcranial direct current stimulation," "stroke," or "cerebrovascular accident".

2.2. Inclusion and Exclusion Criteria. In order to guarantee the quality of articles, we unified the inclusion criteria. The details were as follows: (1) all patients were adults ( $\geq 18$ years) and were diagnosed with a first stroke; (2) the articles were focused on the effect of tDCS on the recovery of motor function in stroke patients; (3) the stimulation sites were located in the primary motor cortex (M1); (4) all experiments were randomized control trials including crossover and parallel design; (5) $\geq 5$ patients were enrolled, and all control groups were sham tDCS; (6) all included articles were peerreviewed and published in English; and (7) the results were measured with scales. The exclusion criteria were as follows: (1) patients who had other diseases that could cause motor dysfunction; (2) articles that had been published but did not provide raw data, such as reviews, meta-analysis, or case reports; (3) animal experiments; and (4) results that were not expressed as mean \pm standard deviation or mean \pm standard error, but as median or interquartile range.

2.3. Literature Quality Assessment. Two reviewers independently completed the methodological quality assessment of 
TABLE 1: Characteristics of the included studies.

\begin{tabular}{|c|c|c|c|c|c|c|c|c|}
\hline Study & $N$ & Mean age (y) & $\begin{array}{c}\text { Time of } \\
\text { poststroke }\end{array}$ & $\begin{array}{l}\text { Study } \\
\text { design }\end{array}$ & $\begin{array}{l}\text { Current density } \\
\left(\mathrm{mA} / \mathrm{cm}^{2}\right)\end{array}$ & Session & $\begin{array}{l}\text { Stimulation } \\
\text { site }\end{array}$ & Out measure \\
\hline Kim et al. 2009 & 10 & $62.8 \pm 13.2$ & $6.4 \pm 3.2 \mathrm{w}$ & Crossover & 0.04 & 1 & $\mathrm{M} 1$ & FA \\
\hline Menezes et al. 2018 & 20 & $56.6 \pm 12.3$ & $5.7 \pm 5.7 y$ & Crossover & NA & 1 & M1 & Pinch strength \\
\hline Tahtis et al. 2014 & 14 & $61.9 \pm 12.9$ & $22.6 \pm 9.4 \mathrm{~d}$ & Parallel & 0.08 & 1 & M1 & TUG \\
\hline Bolognini et al. 2011 & 14 & $46.7 \pm 14.1$ & $35.2 \pm 26.4 \mathrm{~m}$ & RCT & 0.057 & 10 & M1 & FMM \\
\hline Kwon et al. 2016 & 20 & $58.6 \pm 8.4$ & $42.0 \pm 37.5 \mathrm{~m}$ & Crossover & 0.08 & 1 & M1 & Movement time \\
\hline Rabadi et al. 2017 & 16 & $62 \pm 9$ & $6.4 \pm 3.2 \mathrm{~d}$ & RCT & 0.029 & 10 & M1 & ARAT \\
\hline Pavlova et al. 2017 & 11 & $60.7 \pm 11.4$ & $5.5 \pm 9.9 y$ & RCT & 0.014 & 40 & M1 & FMA-UE \\
\hline Mazzoleni et al. 2017 & 24 & $72.63 \pm 10.78$ & $25.38 \pm 12.76 \mathrm{~d}$ & RCT & 0.057 & 30 & M1 & FMA-UE \\
\hline Figlewski et al. 2017 & 44 & $\begin{array}{l}\text { A: } 60 \pm 11 \\
\text { S: } 61 \pm 10\end{array}$ & $\begin{array}{l}\text { A: } 9(3-35) \mathrm{m} \\
\text { S: } 7(3-36) \mathrm{m}\end{array}$ & RCT & 0.043 & 9 & M1 & WMFT FAS \\
\hline Takeuchi et al. 2012 & 18 & $\begin{array}{l}\text { A: } 57 \pm 10.2 \\
\text { S: } 64 \pm 5.8\end{array}$ & $\begin{array}{l}\text { A: } 62.0 \pm 33.2 \mathrm{~m} \\
S: 71.9 \pm 51.0 \mathrm{~m}\end{array}$ & RCT & 0.04 & NA & M1 & Pinch force \\
\hline Marquez et al. 2017 & 25 & $64.28 \pm 11$ & $80.4 \pm 43.5 \mathrm{~m}$ & Crossover & 0.029 & NA & M1 & JTT \\
\hline Straudi et al. 2016 & 23 & $58.2 \pm 14.4$ & $58.6 \pm 52.2 \mathrm{w}$ & RCT & 0.029 & 10 & M1 & FMA-UE \\
\hline Kim et al. 2010 & 18 & $\begin{array}{c}\text { A: } 55.3 \pm 16.4 \\
\text { C: } 53.6 \pm 14.9 \\
\text { S: } 62.9 \pm 9.2\end{array}$ & $\begin{array}{c}\text { A: } 34.0 \pm 27.1 \mathrm{~d} \\
\text { C: } 19.4 \pm 9.3 \mathrm{~d} \\
\text { S: } 22.9 \pm 7.5 \mathrm{~d}\end{array}$ & RCT & 0.08 & 10 & M1 & FMA \\
\hline Goodwill et al. 2016 & 15 & $56.9 \pm 12.3$ & $4.5 \pm 3.3 y$ & RCT & 0.06 & 9 & M1 & MAS \\
\hline Hesse et al. 2011 & 95 & $\begin{array}{c}\text { A: } 63.9 \pm 10.5 \\
\text { C: } 65.4 \pm 8.6 \\
\text { S: } 65.6 \pm 10.3\end{array}$ & $\begin{array}{l}\text { A: } 3.4 \pm 1.8 \mathrm{w} \\
\text { C: } 3.8 \pm 1.4 \mathrm{w} \\
\text { S: } 3.8 \pm 1.5 \mathrm{w}\end{array}$ & RCT & 0.057 & 30 & M1 & FMM \\
\hline Allman et al. 2016 & 24 & $63.5 \pm 11.5$ & $54.1 \pm 36.3 \mathrm{~m}$ & RCT & 0.029 & 9 & M1 & FMA-UE \\
\hline Triccas et al. 2015 & 22 & $63.4 \pm 12.0$ & $19.6 \pm 25.7 \mathrm{~m}$ & RCT & 0.029 & 18 & M1 & FMA \\
\hline Fleming et al. 2017 & 24 & $59.8 \pm 13.1$ & $19.7 \pm 27.4 \mathrm{~m}$ & Crossover & 0.04 & 1 & M1 & JTT \\
\hline Sattler et al. 2015 & 20 & $65.2 \pm 11.3$ & $5.5 \pm 3.2 \mathrm{~d}$ & RCT & 0.034 & 5 & M1 & JHFT \\
\hline Saeys et al. 2015 & 31 & $63.2 \pm 8.7$ & $42.1 \pm 18.9 \mathrm{~d}$ & Crossover & 0.043 & 16 & M1 & The Tinetti test \\
\hline Picelli et al. 2015 & 20 & $\begin{array}{c}\text { A: } 62.8 \pm 11.8 \\
\text { S: } 61.0 \pm 7.2\end{array}$ & $\begin{array}{l}\text { A: } 51.9 \pm 41.1 \mathrm{~m} \\
\text { S: } 54.8 \pm 32.9 \mathrm{~m}\end{array}$ & RCT & 0.057 & 10 & M1 & $6 \mathrm{MWT}$ \\
\hline Chang et al. 2015 & 24 & $62.8 \pm 10.6$ & $16.3 \pm 5.6 \mathrm{~d}$ & RCT & 0.28 & 10 & M1 & FMA-LE \\
\hline Ang et al. 2015 & 19 & $54.1 \pm 10.6$ & $1037 \pm 598 d$ & RCT & NA & 10 & M1 & FMM \\
\hline Fusco et al. 2014 & 16 & $60.4 \pm 14.9$ & $50.9 \pm 20.2 \mathrm{~d}$ & Crossover & 0.043 & 1 & M1 & 9HPT velocity \\
\hline Sohn et al. 2013 & 11 & $58.45 \pm 14.55$ & $63.00 \pm 17.27 \mathrm{~d}$ & Crossover & 0.08 & 1 & M1 & $\begin{array}{l}\text { Isometric peak torque } \\
\text { for knee extensor }\end{array}$ \\
\hline Geroin et al. 2011 & 20 & $\begin{array}{l}\text { A: } 63.7 \pm 6.7 \\
\text { S: } 63.3 \pm 6.4\end{array}$ & $\begin{array}{l}\text { A: } 25.7 \pm 6.0 \mathrm{~m} \\
\text { S: } 26.7 \pm 5.1 \mathrm{~m}\end{array}$ & RCT & 0.043 & 10 & M1 & 10MWT \\
\hline Fusco et al. 2014 & 11 & $58.36 \pm 14.35$ & $19.09 \pm 8.04 \mathrm{~d}$ & RCT & 0.043 & 10 & M1 & FMA-UE/6MWT \\
\hline Klomjai et al. 2018 & 19 & $57.2 \pm 12.3$ & $3.2 \pm 1.7 \mathrm{~m}$ & Crossover & 0.057 & 1 & M1 & FTSTS \\
\hline Hamoudi et al. 2018 & 36 & $\begin{array}{l}\text { A: } 61.9 \pm 12.7 \\
\text { S: } 61.6 \pm 12.7\end{array}$ & $\begin{array}{l}\text { A: } 47.9 \pm 80.6 \mathrm{~m} \\
\text { S: } 43.7 \pm 50.9 \mathrm{~m}\end{array}$ & RCT & 0.04 & 5 & M1 & JTT \\
\hline
\end{tabular}

A: anodal tDCS; S: sham tDCS; C: cathodal tDCS; $N$ : analyzed sample size; FA: finger acceleration; TUG: time up and go; FMM: upper extremity Fugl-Meyer Motor Score; ARAT: Action Research Arm Test; FMA-UE/LE: Fugl-Meyer Assessment-upper/lower extremity; WMFT-FAS: Wolf Motor Function Test-Functional Ability Scale; JTT: Jebsen Taylor Test; MAS: Motor Assessment Scale; JHFT: the Jebsen Taylor Hand Function Test; 6MWT: 6-minute walk test; 9HPT: the 9-hole peg test; 10MWT: 10-minute walking test; FTSTS: Five-Times-Sit-To-Stand; NA: not mentioned. All data are shown as the mean \pm standard deviation or median (range).

the included articles by using a modified checklist from Moher et al. [27]. If the opinions were inconsistent, a third reviewer reevaluated the articles and discussed with the two reviewers to reach an agreement. The specific criteria were as follows: (1) randomization; (2) blind procedure; (3) baseline data description; (4) control study; (5) 
dropout number; and (6) side effects. Randomization was recorded as " 1 " if the random distribution method was used in the study and "0" if not. For the blinded method, " 0 " represented the nonblinded procedure, and " 1 " and " 2 " represented the single and double-blind procedures, respectively. If baseline data was given, it was denoted as " 1 " and was denoted as "0" if not. The control design was recorded as " 1 " if the experiment was designed with a healthy control group, " 2 " with a patient control group, and " 3 " with both control groups. Dropout number and side effects were recorded as a number of events.

2.4. Data Extraction and Analyses. Two experienced reviewers completed the data extraction independently. The basic information included sample size, mean age, time of poststroke, study design, stimulation parameters (current density, session), stimulation site, and outcome measurements. If no change data was given in the article, the data of prestimulation and poststimulation was extracted. If only the graph was given in the article, we used the software of GetData Graph Digitizer 2.25 (http://getdata-graphdigitizer.com/) to get useful data.

An immediate effect was performed to investigate the curative effect on motor function recovery of stroke patients between real and sham tDCS. The following subgroup analyses were performed: polarity (anode vs. cathode vs. bilateral), stroke stage (acute vs. subacute vs. chronic), current density $\left(\leq 0.029 \mathrm{~mA} / \mathrm{cm}^{2}\right.$ vs. $\left.>0.029 \mathrm{~mA} / \mathrm{cm}^{2}\right)$, and treatment sessions ( $\leq 10$ sessions vs. $>10$ sessions).

Review Manager Software version 5.3 (Cochrane Collaboration, Oxford, England) was used to analyze data in this meta-analysis. The effect of tDCS was expressed as the standardized mean difference (SMD) with 95\% confidence interval (CI). The heterogeneity was estimated by using Cochran's $Q$ test and $I^{2}$ test. If the $I^{2}$ value was smaller than $50 \%$, the fixed effects model was used; otherwise, a random effects model was used. View publication bias with a funnel plot. A statistically significant $P$ value was set to 0.05 .

\section{Result}

3.1. Literature Selection. By searching the four databases mentioned above, a total of 2,197 articles were found. Finally, only 29 studies were included in this meta-analysis based on the inclusion and exclusion criteria. The specific flow chart is shown in Figure 1.

3.2. Literature Characteristics. In the final included articles, stroke patients enrolled in two articles were in the acute phase $[10,28], 11$ in the subacute phase, and 13 in the chronic phase. The remaining three papers recruited both subacute and chronic stroke patients. With regard to the experimental method, all the included studies were randomized control trials. As for the treatment parameters of tDCS, the current density ranged from $0.014 \mathrm{~mA} / \mathrm{cm}^{2}$ to $0.28 \mathrm{~mA} / \mathrm{cm}^{2}$. For sessions, at least one session up to 40 sessions of tDCS were performed. The stimulation sites of all included articles were M1. All included subjects suffered their first ever unilateral stroke. The main characteris-
TABLE 2: Quality appraisal of the included studies.

\begin{tabular}{|c|c|c|c|c|c|c|}
\hline Study & 1 & 2 & 3 & 4 & 5 & 6 \\
\hline Kim et al. 2009 & 1 & 1 & 1 & 2 & 0 & 0 \\
\hline Menezes et al. 2018 & 1 & 2 & 1 & 2 & 2 & NA \\
\hline Tahtis et al. 2014 & 1 & 2 & 1 & 2 & 0 & 0 \\
\hline Bolognini et al. 2011 & 1 & 2 & 1 & 2 & 0 & 0 \\
\hline Kwon et al. 2016 & 1 & 2 & 1 & 2 & 0 & 0 \\
\hline Rabadi et al. 2017 & 1 & 2 & 1 & 2 & 0 & 1 \\
\hline Pavlova et al. 2017 & 1 & 1 & 1 & 2 & 0 & 0 \\
\hline Mazzoleni et al. 2017 & 1 & 1 & 1 & 2 & 0 & 0 \\
\hline Figlewski et al. 2017 & 1 & 0 & 1 & 2 & 0 & 4 \\
\hline Takeuchi et al. 2012 & 1 & 1 & 1 & 2 & 0 & 0 \\
\hline Marquez et al. 2017 & 1 & 2 & 1 & 2 & 0 & 0 \\
\hline Straudi et al. 2016 & 1 & 2 & 1 & 2 & 0 & 4 \\
\hline Kim et al. 2010 & 1 & 1 & 1 & 2 & 2 & 2 \\
\hline Goodwill et al. 2016 & 1 & 2 & 1 & 2 & 0 & 0 \\
\hline Hesse et al. 2011 & 1 & 2 & 1 & 2 & 1 & 2 \\
\hline Allman et al. 2016 & 1 & 2 & 1 & 2 & 2 & NA \\
\hline Triccas et al. 2015 & 1 & 2 & 1 & 2 & 1 & 7 \\
\hline Fleming et al. 2017 & 1 & 1 & 1 & 2 & 1 & 1 \\
\hline Sattler et al. 2015 & 1 & 2 & 1 & 2 & 0 & 1 \\
\hline Saeys et al. 2015 & 1 & 2 & 1 & 2 & 0 & 0 \\
\hline Picelli et al. 2015 & 1 & 2 & 1 & 2 & 0 & 0 \\
\hline Chang et al. 2015 & 1 & 2 & 1 & 2 & 0 & NA \\
\hline Ang et al. 2015 & 1 & 0 & 1 & 2 & 0 & $\mathrm{NA}$ \\
\hline Fusco et al. 2014 & 1 & 2 & 1 & 2 & 2 & 3 \\
\hline Sohn et al. 2013 & 1 & 0 & 1 & 2 & 0 & $\mathrm{NA}$ \\
\hline Geroin et al. 2011 & 1 & 0 & 1 & 2 & 0 & 0 \\
\hline Fusco et al. 2014 & 1 & 2 & 1 & 2 & 3 & 1 \\
\hline Klomjai et al. 2018 & 1 & 2 & 1 & 2 & 0 & 3 \\
\hline Hamoudi et al. 2018 & 1 & 1 & 1 & 2 & 2 & 0 \\
\hline
\end{tabular}

1: randomly assigned; 2 : blind process; 3 : baseline data description; 4 : control study; 5: dropouts; 6: side effect; NA: not mentioned.

tics and the quality assessment of the included studies are shown in Tables 1 and 2, respectively.

3.3. Adverse Effect. A total of 11 articles showed side effects; three studies reported a tingling sensation under the electrodes [10, 28, 29]. Fleming et al. reported one patient quit due to a headache after the first intervention [30]. Triccas et al. mentioned one patient dropped out due to a skin reaction after receiving treatment and other side effects could be accepted by the remaining patients [31]. In the experiment of Kim et al., two subjects discontinued tDCS, one was due to headache and the other was because of dizziness [32]. Pain occurred in both groups in the study of Fusco et al. [33]. Light flashes, fatigue or warmth, etc. occurred in another four studies, but all subjects could endure and complete treatments. The remaining 18 articles either had not side effects or were not mentioned in the articles. 


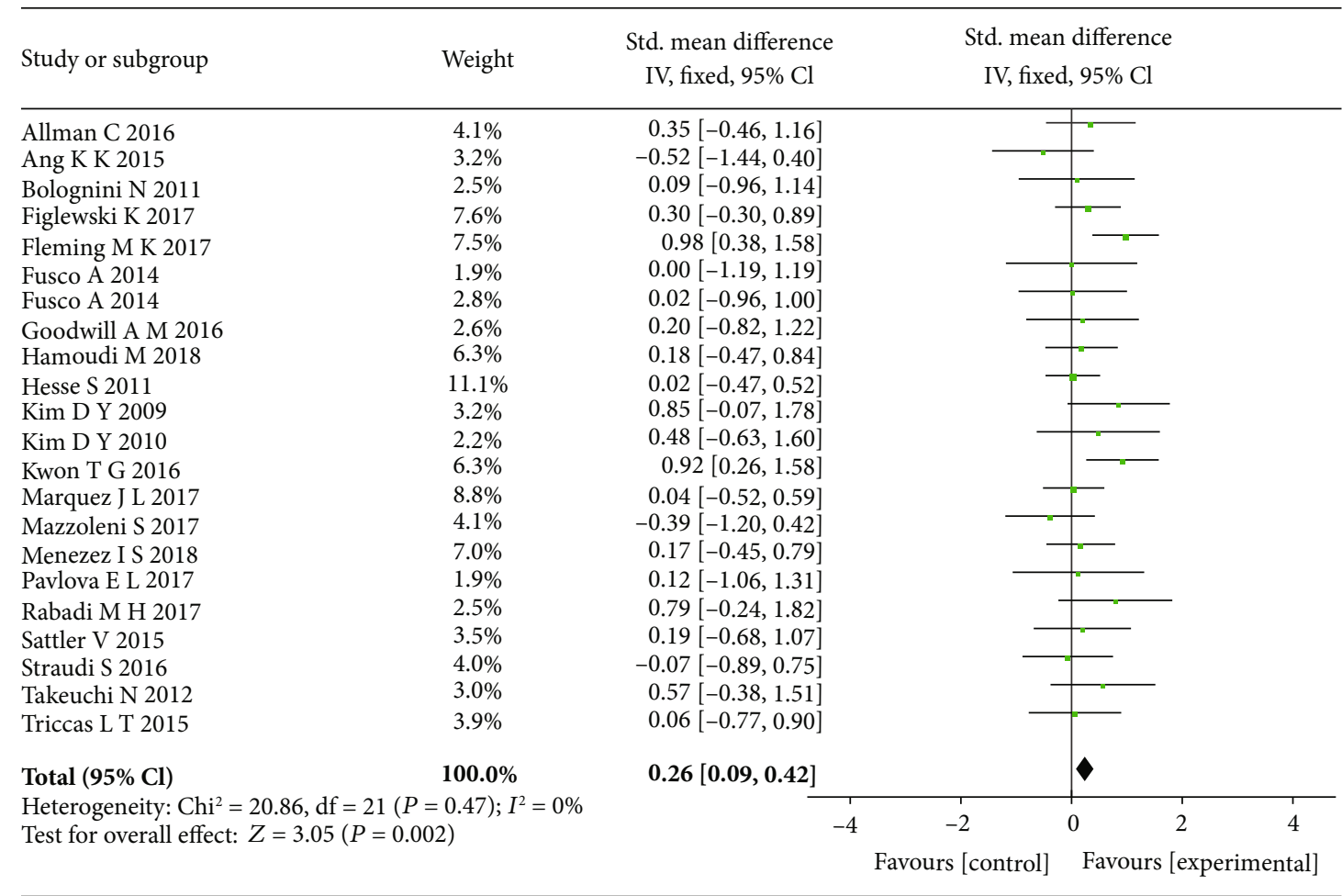

(a)

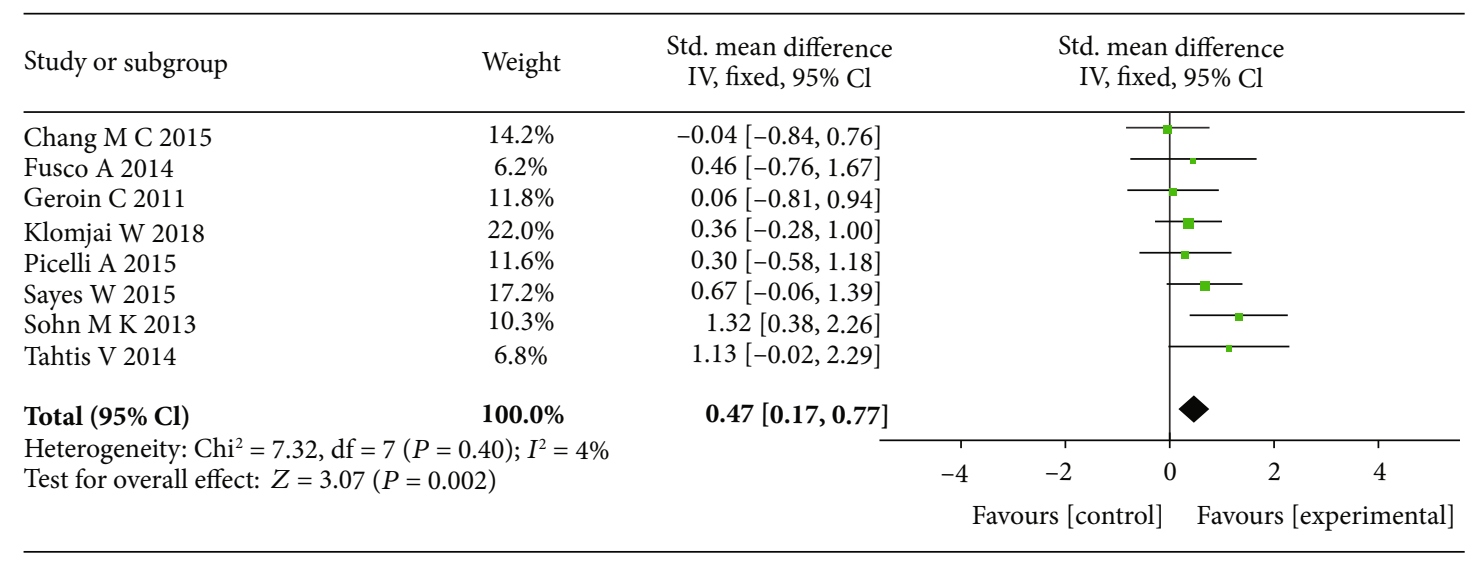

(b)

FIGURE 2: The forest plots of the overall effect of tDCS on upper (a) and lower (b) limb motor functions in stroke patients.

\section{Results of Meta-Analysis}

4.1. Overall Effect of $t D C S$. The pooled results showed that tDCS was effective to upper limb $(\mathrm{SMD}=0.26,95 \% \mathrm{CI}$ : $\left.0.09-0.42, P=0.002, I^{2}=0 \%\right)$ and lower limb $(\mathrm{SMD}=0.47$, 95\% CI: $\left.0.17-0.77, P=0.002, I^{2}=4 \%\right)$ function in stroke patients (Figure 2). The corresponding funnel plots above were approximately symmetrical and closed to the center line which indicated very small publication bias (Figure 3 ).

4.2. Upper Limb: Immediate Effect of tDCS to Different Stages of Stroke Patients. According to the duration of stroke, the included studies were divided into the acute, subacute, and chronic groups. The comparison of the pooled results showed that the tDCS only revealed a significant effect
$\left(\mathrm{SMD}=0.25,95 \% \mathrm{CI}: 0.02-0.47, P=0.03, I^{2}=0 \%\right)$ in the patients of the chronic group (Figure 4).

4.3. Upper Limb: The Parameters of tDCS. The subgroup analysis of polarity showed that both the anode tDCS $\left(\mathrm{SMD}=0.25,95 \% \mathrm{CI}: 0.06-0.43, P=0.01, I^{2}=0 \%\right)$ and cathode tDCS $(\mathrm{SMD}=0.41,95 \% \mathrm{CI}: 0.15-0.67, P=0.002$, $\left.I^{2}=35 \%\right)$ were significantly effective on upper limb function recovery (Figure 5). Therefore, further subgroup analyses of sessions and current density were conducted based on the anode and cathode tDCS studies separately.

The subgroup analysis of sessions revealed that the significant mean effect sizes were observed when $\leq 10$ sessions of $\mathrm{tDCS}$ were given in both the anode $\mathrm{tDCS}(\mathrm{SMD}=0.40$, 95\% CI: $0.16-0.65, P=0.001, I^{2}=0 \%$ ) (Figure 6(a)) and 


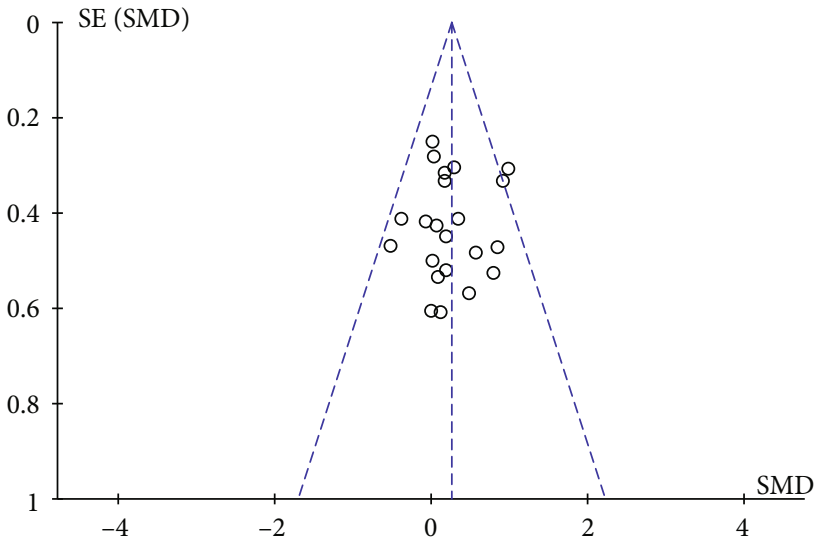

(a)

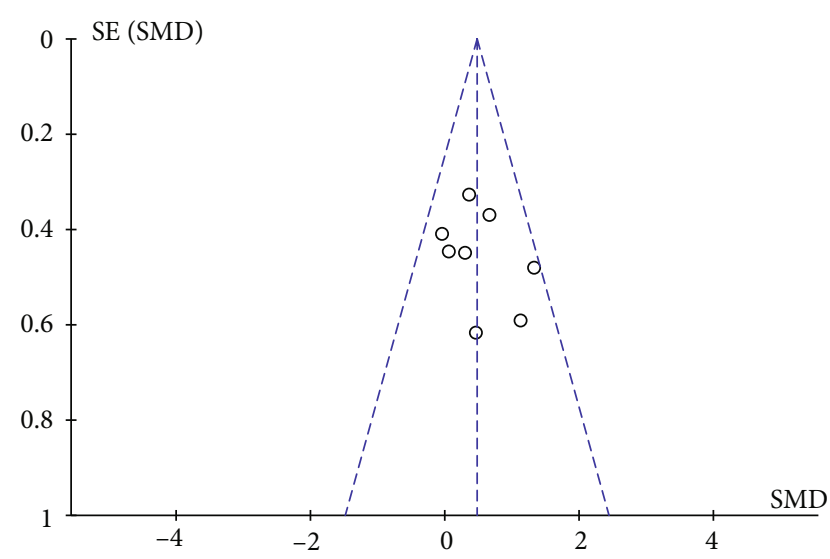

(b)

FIGURE 3: The funnel plots of the overall analysis of studies on upper (a) and lower limb (b) functions of stroke patients.

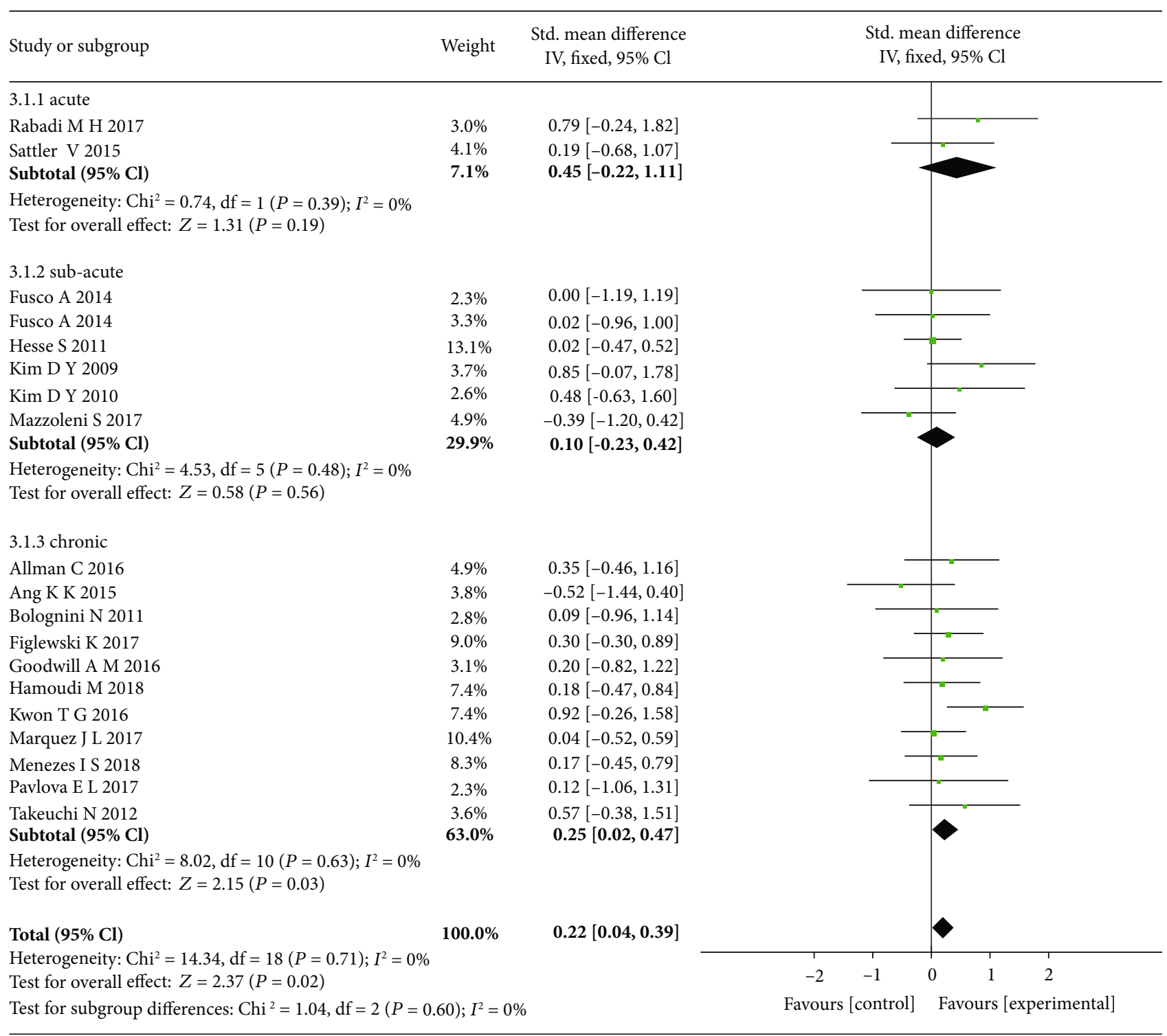

FIGURE 4: The forest plot shows more significant effect size of tDCS on chronic stroke patients with upper limb motor dysfunction than acute and subacute stroke patients. 


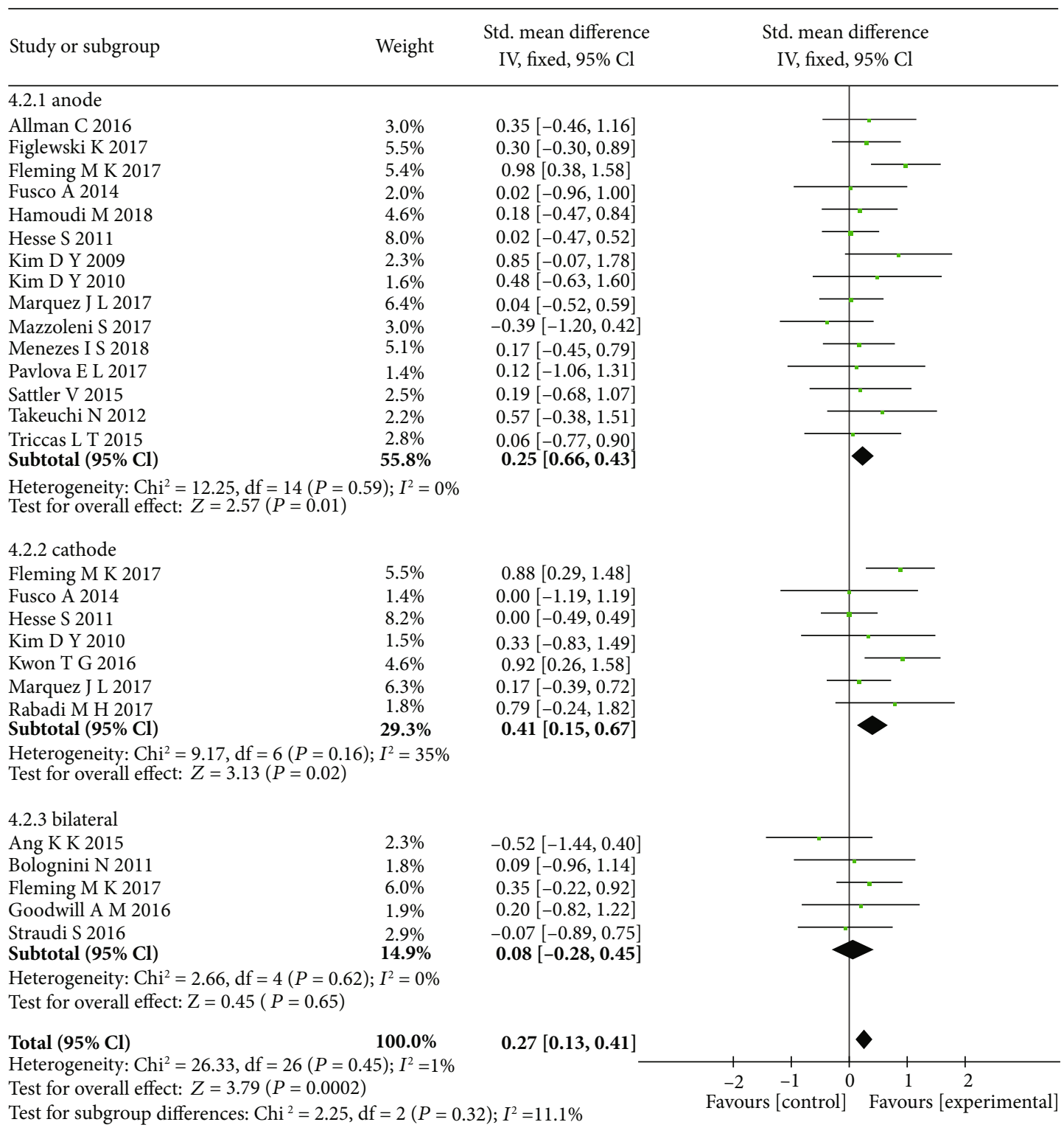

FIGURE 5: The forest plot shows more significant effect sizes of anode and cathode tDCS than bilateral tDCS on upper limb motor function in stroke patients.

cathode tDCS groups $(\mathrm{SMD}=0.79,95 \% \mathrm{CI}: 0.43-1.16$, $P<0.0001, I^{2}=0 \%$ ) (Figure 6(b)).

For the stimulation current density, we observed that the mean effect sizes were more significant when the current density of tDCS was more than $0.029 \mathrm{~mA} / \mathrm{cm}^{2}$ on the basis of $\leq 10$ sessions also in both the anode tDCS (SMD $=0.46$, 95\% CI: $0.17-0.74, P=0.002, I^{2}=0 \%$ ) (Figure $7(\mathrm{a})$ ) and cathode tDCS groups $(\mathrm{SMD}=0.79,95 \% \mathrm{CI}: 0.40-1.18, P<0.0001$, $I^{2}=0 \%$ ) (Figure $7(\mathrm{~b})$ ).

4.4. Lower Limb: Immediate Effect of tDCS to Stroke Patients. The data of six studies were summarized and found that tDCS had a better significant effect on the recovery of lower limb function in sub-acute stroke patients $(\mathrm{SMD}=0.56,95 \% \mathrm{CI}$ : $0.22-0.90, P=0.001, I^{2}=18 \%$ ) (Figure 8 ), especially bihemi- spheric tDCS stimulation $(\mathrm{SMD}=0.59,95 \% \mathrm{CI}: 0.14-1.03$, $P=0.009, I^{2}=0 \%$ ) (Figure 9).

\section{Discussion}

Although many articles have proved that tDCS was beneficial to motor function recovery after stroke, few have analyzed the specific parameters. In this meta-analysis, we observed the positive effects of tDCS on the recovery of limb motor function after stroke. This was consistent with Edwardson et al. [34], but some differences existed between upper and lower limbs in tDCS parameters.

In terms of tDCS stimulation mode, we found that both the anode and cathode were beneficial to the recovery of upper limb motor function after stroke, which is in 


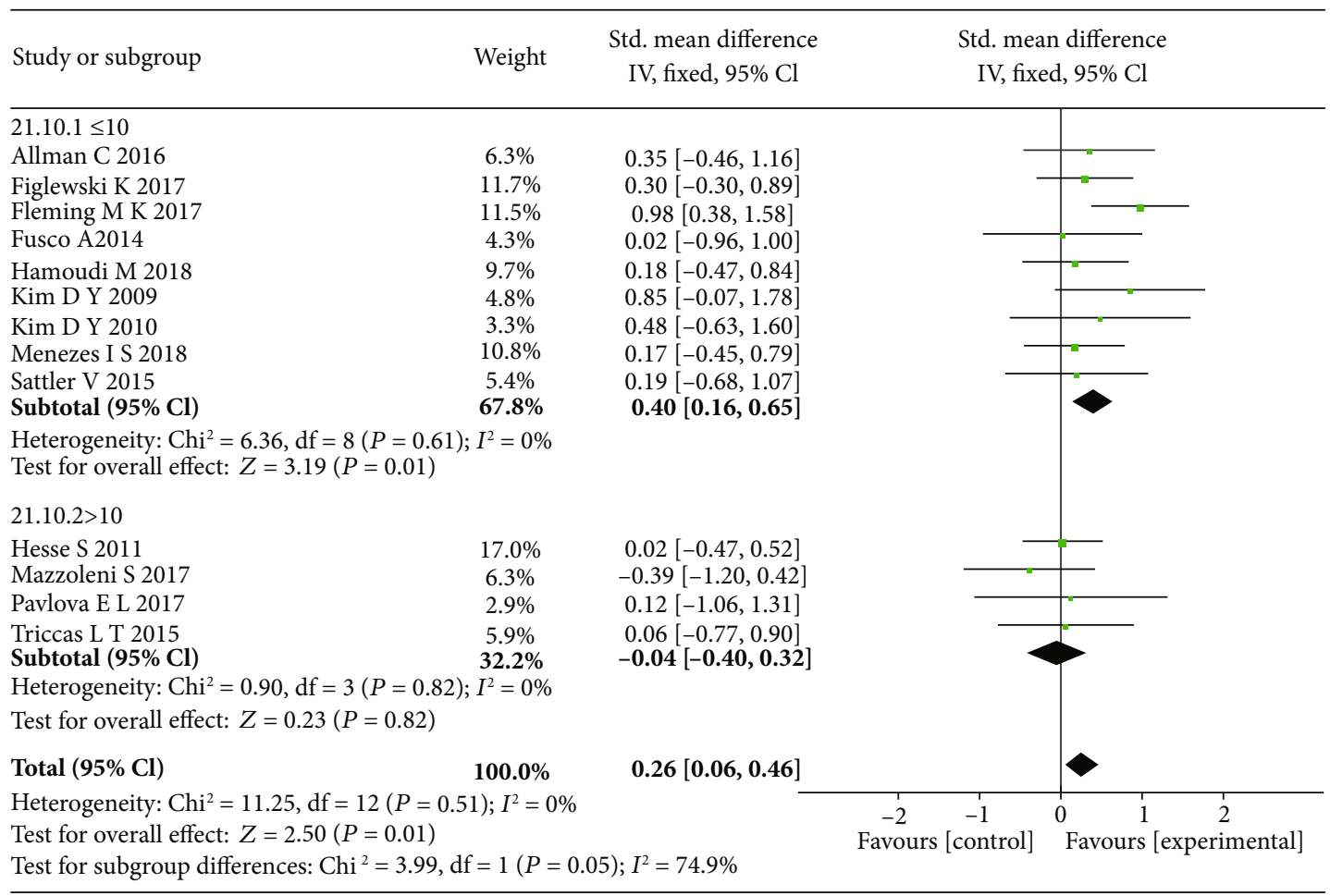

(a)

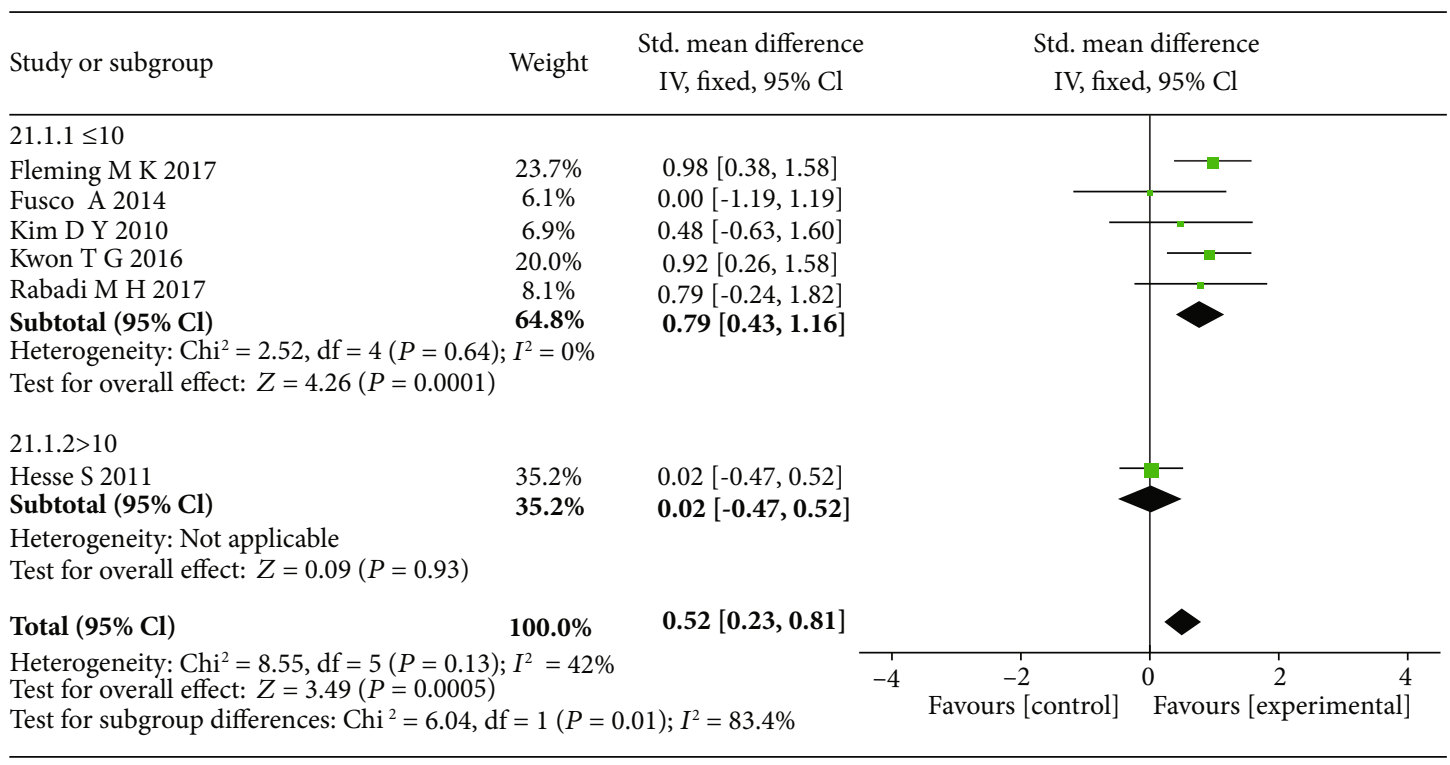

(b)

FIGURE 6: The forest plots of the subgroup analyses of treatment session of both anode (a) and cathode (b) tDCS show more significant effect sizes when $\leq 10$ sessions on upper limb motor function in stroke patients.

accordance with a previous review by Lüdemann-Podubecká et al. [25]. Two other papers had a similar conclusion that tDCS was beneficial to upper limb function in stroke patients $[20,24]$. Although another meta-analysis reported that the effect of anode tDCS on stroke patients with motor dysfunction was not significant, it was positive for the motor recovery [19]. Furthermore, the increased corticomotor excitability was also observed in both stroke and healthy subjects in this study. Therefore, tDCS has a positive effect on the motor recovery of stroke patients, and its therapeutic effect may be related to the modulation of the neural activity between interhemispheres. The motor cortical excitability was imbalanced after stroke, due to the overactive unaffected hemisphere which increased the inhibition to the affected hemisphere [35]. The cathode or anode tDCS could promote the recovery of motor function by inhibiting the 


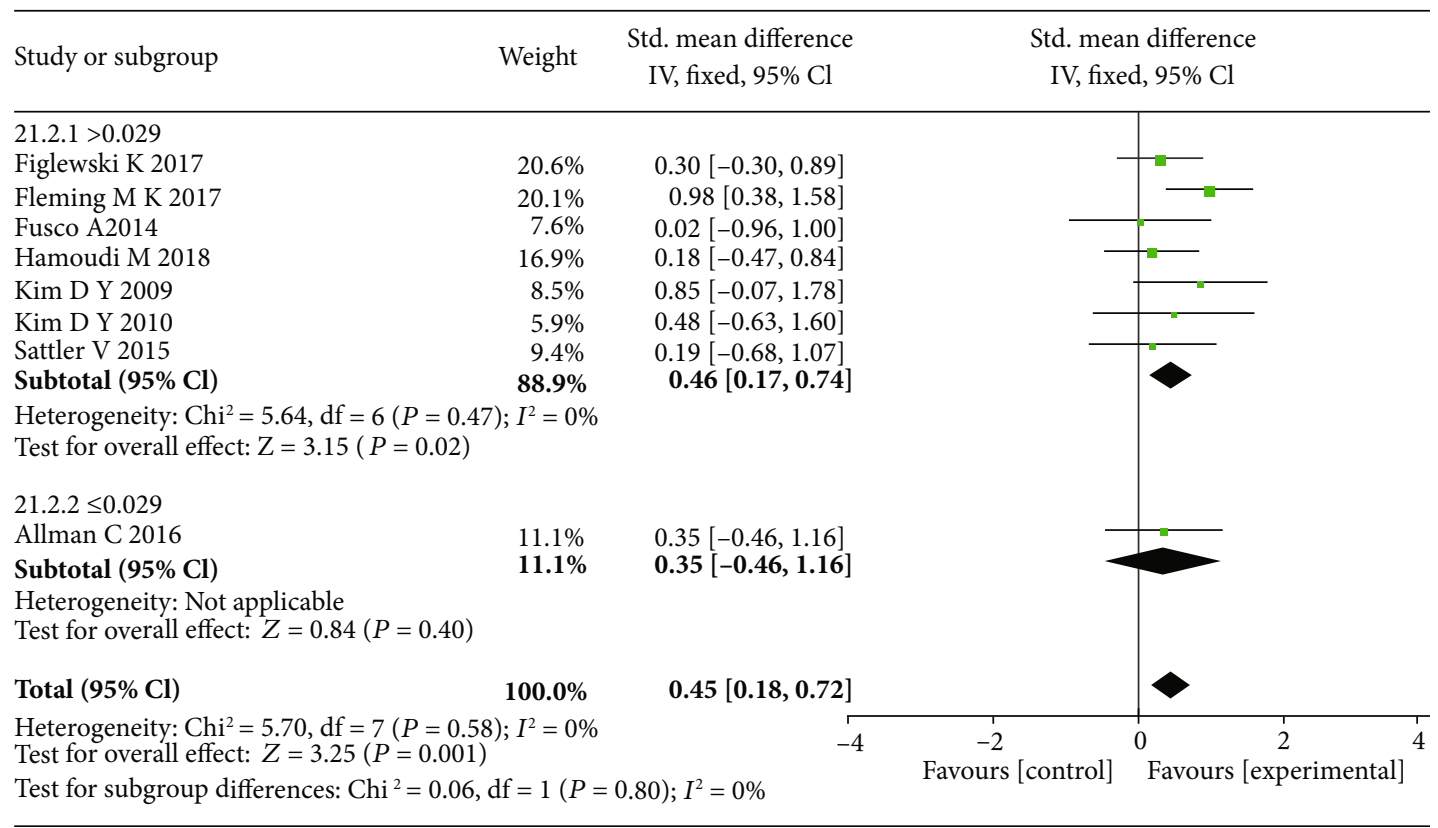

(a)

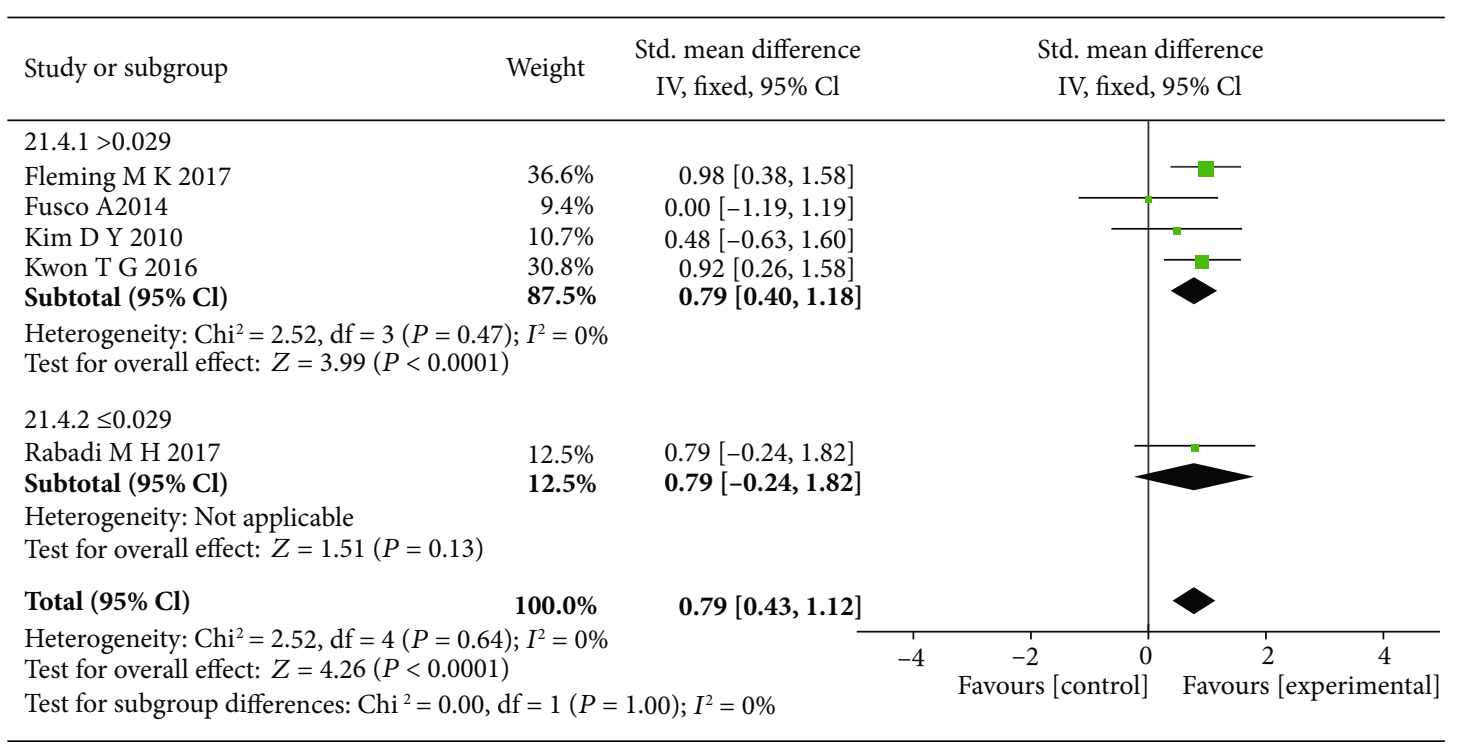

(b)

FIGURE 7: The forest plots of the subgroup analyses of stimulation density of both anode (a) and cathode (b) tDCS show more significant effect sizes when $\leq 10$ sessions and the current density $>0.029 \mathrm{~mA} / \mathrm{cm}^{2}$ on upper limb motor function in stroke patients.

hyperactivity of the unaffected motor cortex or activating the injured motor cortex [36].

In further subgroup analysis on stroke stages, we found that the therapeutic effect of tDCS was better in chronic stroke patients than acute and subacute patients with upper limb disorder. This is consistent with the results in Jodie Marquez et al. [37]. Lüdemann-Podubecká et al. also held the same view that tDCS existed a positive effect in chronic stroke with upper limb dysfunction [25]. The excitability of the corticospinal is different in the subacute and chronic phases during stroke rehabilitation. Several functional magnetic resonance imaging studies of the brain have shown that the unaffected hemisphere is overactive after stroke. The hyperactivity leads to a less effect on the recovery of affected hand function in the subacute phase, but a better effect on the chronic phase $[20,38,39]$. However, the specific mechanism in this phenomenon was not very clear. It may be due to that after three to six months, neural recovery reached peak and remained stable $[40,41]$. In addition, a study reported that short latency afferent inhibition (a marker of central cholinergic activity) was suppressed at the acute phase, but increased at six months, which was associated with better recovery of motor function [42].

One previous meta-analysis demonstrated that a positive dose-response relationship existed between current density and recovery of motor function after stroke [43]. This is in 


\begin{tabular}{|c|c|c|c|c|c|c|}
\hline Study or subgroup & Weight & $\begin{array}{l}\text { Std. mean difference } \\
\text { IV, fixed, } 95 \% \mathrm{Cl}\end{array}$ & \multicolumn{4}{|c|}{$\begin{array}{l}\text { Std. mean difference } \\
\text { IV, fixed, } 95 \% \mathrm{Cl}\end{array}$} \\
\hline \multicolumn{7}{|l|}{ 7.4.1 sub-acute } \\
\hline Chang M C 2015 & $14.2 \%$ & \multicolumn{2}{|l|}{$-0.04[-0.84,0.76]$} & 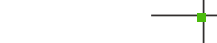 & & \\
\hline Fusco A 2014 & $6.2 \%$ & \multicolumn{2}{|l|}{$0.46[-0.76,1.67]$} & & & \\
\hline Klomjai W 2018 & $22.0 \%$ & \multicolumn{2}{|l|}{$0.36[-0.28,1.00]$} & & & \\
\hline Saeys W 2015 & $17.2 \%$ & \multicolumn{2}{|l|}{$0.67[-0.06,1.39]$} & & & \\
\hline Sohn M K 2013 & $10.3 \%$ & & & & \\
\hline Tahtis V 2014 & $6.8 \%$ & & & & & \\
\hline Subtotal $(95 \% \mathrm{Cl})$ & $76.6 \%$ & \multicolumn{2}{|l|}{$0.56[0.22,0.90]$} & & & \\
\hline \multicolumn{7}{|c|}{ Heterogeneity: $\mathrm{Chi}^{2}=6.09, \mathrm{df}=5(P=0.30) ; I^{2}=18 \%$} \\
\hline \multicolumn{7}{|c|}{ Test for overall effect: $Z=3.19(P=0.001)$} \\
\hline \multicolumn{7}{|l|}{ 7.4.2 chronic } \\
\hline Geroin C 2011 & $11.8 \%$ & \multicolumn{2}{|l|}{$0.06[-0.81,0.94]$} & \multirow{3}{*}{$\longrightarrow$} & & \\
\hline Picelli A 2015 & $11.6 \%$ & $0.30[-0.58,1.18]$ & & & & \\
\hline Subtotal $(95 \% \mathrm{Cl})$ & $23.4 \%$ & $0.18[-0.44,0.80]$ & & & & \\
\hline \multicolumn{7}{|c|}{ Heterogeneity: $\mathrm{Chi}^{2}=0.14, \mathrm{df}=1(P=0.71) ; I^{2}=0 \%$} \\
\hline \multicolumn{7}{|c|}{ Test for overall effect: $Z=0.57(P=0.57)$} \\
\hline Total $(95 \% \mathrm{Cl})$ & $100.0 \%$ & $0.47[0.17,0.77]$ & & & & \\
\hline \multicolumn{3}{|c|}{$\begin{array}{l}\text { Heterogeneity: } \mathrm{Chi}^{2}=7.32, \mathrm{df}=7(P=0.40) ; I^{2}=0 \% \\
\text { Test for overall effect: } Z=3.07(P=0.002) \\
\text { Test for subgroup differences: } \mathrm{Chi}^{2}=1.09, \mathrm{df}=1(P=0.30) ; I^{2}=8.1 \%\end{array}$} & -4 & $\begin{array}{c}-2 \\
\text { Favours [control] }\end{array}$ & $\begin{array}{rr}0 & 2 \\
& \text { Favours [ }\end{array}$ & $\begin{array}{cc}2 & 4 \\
\text { [experimental] }\end{array}$ \\
\hline
\end{tabular}

Figure 8: The forest plot shows more significant effect size of tDCS on subacute stroke patients with lower limb motor dysfunction.

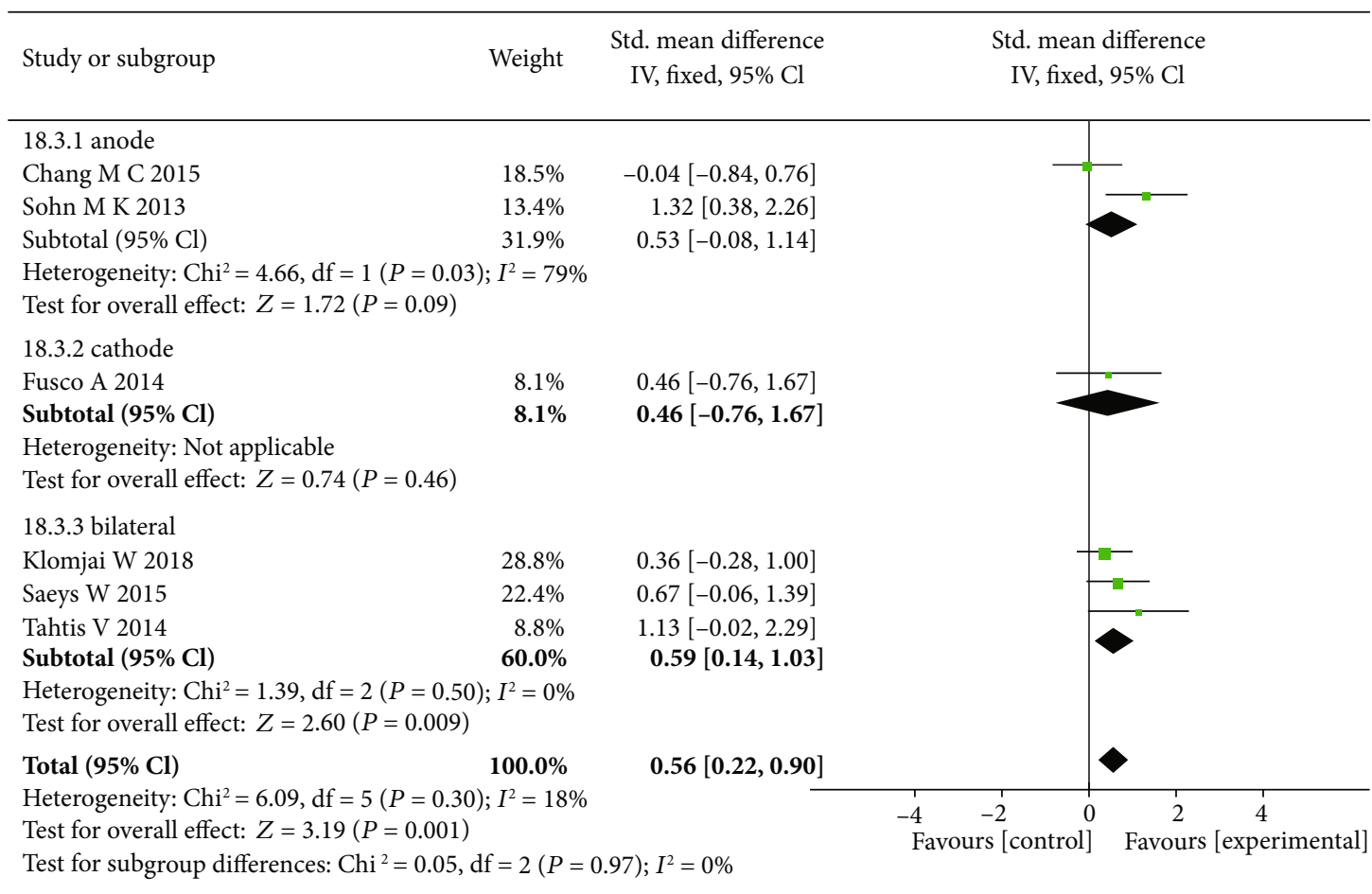

FIGURE 9: The forest plot shows more significant effect size of bilateral tDCS on lower limb motor function in subacute stroke patients.

line with the results of our meta-analysis. Nitsche et al. found that the membrane depolarization or hyperpolarization induced by tDCS was determined by the current density. The larger the current density, the better the effect of tDCS [44]. Another systematic review and meta-analysis indicated that the efficacy of anode tDCS depended on the current density and duration of stimulation [19]. They observed that the effect of current density above $0.029 \mathrm{~mA} / \mathrm{cm}^{2}$ was more significant than that below $0.029 \mathrm{~mA} / \mathrm{cm}^{2}$. However, they subsequently found that the changes in corticospinal excitability caused by the current density of anode tDCS at $0.013 \mathrm{~mA} / \mathrm{cm}^{2}$ were significantly larger than that at $0.029 \mathrm{~mA} / \mathrm{cm}^{2}$ [45]. They believed that the current density at $0.013 \mathrm{~mA} / \mathrm{cm}^{2}$ is sufficient to activate calcium channels 
and increase intracellular calcium content, which leads to neuron depolarization. But they also found that when the current density was above $0.029 \mathrm{~mA} / \mathrm{cm}^{2}$, there was a direct relationship between the current density and the corticospinal excitability changes. This finding is partially in agreement with Nitsche et al. The difference could be explained in two aspects. On the one hand, the stimulation duration of this study was longer than that of Nitsche et al.'s. On the other hand, different electrode sizes were used in the studies of Bastani et al. $\left(24 \mathrm{~cm}^{2}\right)$ and Nitsche et al. $\left(35 \mathrm{~cm}^{2}\right)$, respectively. In addition, the higher the current density, the deeper the electrical field penetrated, which could change the excitability of the undamaged neurons. If the electrode size was too large, it not only stimulated the target region but also influenced the adjacent cortex. Moreover, there is a direct relationship between current density and side effects [45]. The accumulated toxic substance in sponge electrodes may also cause anodal skin lesions [40]. Therefore, an optimal but not maximum current density may exist, which could produce the best therapeutic effect for stroke patients. This is an issue that should be resolved in the future studies.

The same as the current density, the treatment session also influences the effect of tDCS. In this study, we found that the effect of $t D C S \leq 10$ sessions on upper limb function recovery in stroke patients was significantly higher than that of other sessions both with anode and cathode stimulation. This coincided with the conclusion of Chhatbar et al., in which a dose-response relationship was not found in the number of session [43]. Lindenberg et al. also showed that the linear response was not necessarily existed between session and tDCS effect [46]. Therefore, it is not that the number of sessions the patient accepted, but the better the outcome will be. In terms of session, few researches have discussed it. Therefore, more studies are needed to explore this question further.

Prior to this study, a few meta-analyses were published on the recovery of lower extremity motor function after stroke. In our study, we found that bilateral tDCS significantly improved lower limb function in subacute stroke, as reported in the studies of Saeys et al. and Tahtis et al. They both suggested that bihemispheric stimulation made a good effect to lower limb function in subacute stroke $[47,48]$. Bilateral $\mathrm{tDCS}$ reduces the excitability of the contralesional cortex and improves that of the ipsilesional cortex by placing anode on the affected side and cathode on the unaffected side. Therefore, bilateral tDCS is more conductive to reaching balance between the cerebral hemispheres. Feng et al. and Vines et al. also suggested that tDCS stimulated motor cortex simultaneously which was ideal to improve motor function $[36,49]$. A suggestion about tDCS montage was put forward, prompting that bilateral stimulation was better than anode or cathode alone [11, 49, 50]. In a recent meta-analysis of lower extremities, tDCS performed well in mobility and muscle strength in patients with subacute stroke, but poorly in walking speed and balance function [26]. This was consistent with a part of our results. In our study, we also analyzed the polarity of tDCS but did not carry out a more detailed subgroup analysis. Several papers have mentioned that tDCS could increase the neural plasticity, improve motor function during spontaneous recovery, and reach maximum recovery in the first three months $[34,51]$. This coincides with our results; that is, tDCS has a better therapeutic effect on subacute stage.

5.1. Limitation. There are still many details that could be improved in our meta-analysis. For example, only English studies were included in this study that may lead to publication bias. We did not limit the lesion of stroke (cortical or subcortical), nor did we summarize the follow-up results. In addition, most of the included studies enrolled ischemic stroke patients; whether these results are suitable for patients with hemorrhagic stroke still needs to be discussed further. In future studies, these mentioned aspects should be paid more attention.

\section{Conclusion}

tDCS is effective for the recovery of stroke patients with limb dysfunction after the first unilateral stroke, but the optimal parameters of tDCS for the upper and lower limbs are different. tDCS has a great impact on the recovery of upper limb function in chronic stroke patients. In addition, stroke patients with upper limb hemiplegia recover better by using anode or cathode tDCS with above $0.029 \mathrm{~mA} / \mathrm{cm}^{2}$ current density and $\leq 10$ sessions of treatment. But for the recovery of lower limb function, subacute stroke patients benefit more from bilateral tDCS.

\section{Conflicts of Interest}

The authors declare that they have no conflicts of interest.

\section{Authors' Contributions}

$\mathrm{XB}$ and ZG designed and wrote this study. $\mathrm{XB}, \mathrm{ZG}$, and $\mathrm{LH}$ performed the statistical analysis and analyzed the data. LR, $\mathrm{ZG}$, and $\mathrm{MM}$ contributed in modifying the article. QM reviewed and contributed to the full manuscript. Xi Bai and Zhiwei Guo contributed equally to this work.

\section{Acknowledgments}

This work was supported by the National Natural Science Foundation of China (no. 81271559).

\section{References}

[1] A. Miniño, S. Murphy, J. Xu, and K. Kochanek, "Deaths: final data for 2008," National Vital Statistics Reports, vol. 59, no. 10, pp. 1-126, 2011.

[2] M. Menken, T. Munsat, and J. Toole, "The global burden of disease study: implications for neurology," Archives of Neurology, vol. 57, no. 3, pp. 418-420, 2000.

[3] G. Jayaram and J. Stinear, "The effects of transcranial stimulation on paretic lower limb motor excitability during walking," Journal of Clinical Neurophysiology, vol. 26, no. 4, pp. 272-279, 2009.

[4] R. Traversa, P. Cicinelli, P. Pasqualetti, M. Filippi, and P. Rossini, "Follow-up of interhemispheric differences of motor evoked potentials from the 'affected' and 'unaffected' 
hemispheres in human stroke," Brain Research, vol. 803, no. 12, pp. 1-8, 1998.

[5] N. Sharma and L. Cohen, "Recovery of motor function after stroke," Developmental Psychobiology, vol. 54, no. 3, pp. 254262, 2012.

[6] G. Di Pino, G. Pellegrino, G. Assenza et al., "Modulation of brain plasticity in stroke: a novel model for neurorehabilitation," Nature Reviews Neurology, vol. 10, no. 10, pp. 597-608, 2014.

[7] E. Taub, G. Uswatte, and R. Pidikiti, "Constraint-induced movement therapy: a new family of techniques with broad application to physical rehabilitation-a clinical review," Journal of Rehabilitation Research and Development, vol. 36, no. 3, pp. 237-251, 1999.

[8] S. Wolf, C. Winstein, J. Miller et al., "Effect of constraintinduced movement therapy on upper extremity function 3 to 9 months after stroke: the EXCITE randomized clinical trial," Journal of the American Medical Association, vol. 296, no. 17, pp. 2095-2104, 2006.

[9] A. Lo, P. Guarino, H. Krebs et al., "Multicenter randomized trial of robot-assisted rehabilitation for chronic stroke: methods and entry characteristics for VA ROBOTICS," Neurorehabilitation and Neural Repair, vol. 23, no. 8, pp. 775-783, 2009.

[10] M. H. Rabadi and C. E. Aston, "Effect of transcranial direct current stimulation on severely affected arm-hand motor function in patients after an acute ischemic stroke: a pilot randomized control trial," American Journal of Physical Medicine \& Rehabilitation, vol. 96, 10 Suppl 1, pp. S178-S184, 2017.

[11] M. Bikson, P. Grossman, C. Thomas et al., "Safety of transcranial direct current stimulation: evidence based update 2016," Brain Stimulation, vol. 9, no. 5, pp. 641-661, 2016.

[12] L. V. M. Aparicio, F. Guarienti, L. B. Razza, A. F. Carvalho, F. Fregni, and A. R. Brunoni, "A systematic review on the acceptability and tolerability of transcranial direct current stimulation treatment in neuropsychiatry trials," Brain Stimulation, vol. 9, no. 5, pp. 671-681, 2016.

[13] A. R. Brunoni, J. Amadera, B. Berbel, M. S. Volz, B. G. Rizzerio, and F. Fregni, "A systematic review on reporting and assessment of adverse effects associated with transcranial direct current stimulation," The International Journal of Neuropsychopharmacology, vol. 14, no. 8, pp. 1133-1145, 2011.

[14] D. Nowak, C. Grefkes, M. Ameli, and G. Fink, "Interhemispheric competition after stroke: brain stimulation to enhance recovery of function of the affected hand," Neurorehabilitation and Neural Repair, vol. 23, no. 7, pp. 641-656, 2009.

[15] M. Nitsche, P. Boggio, F. Fregni, and A. Pascual-Leone, "Treatment of depression with transcranial direct current stimulation (tDCS): a review," Experimental Neurology, vol. 219, no. 1, pp. 14-19, 2009.

[16] D. Murphy, P. Boggio, and F. Fregni, “Transcranial direct current stimulation as a therapeutic tool for the treatment of major depression: insights from past and recent clinical studies," Current Opinion in Psychiatry, vol. 22, no. 3, pp. 306-311, 2009.

[17] A. Wu, F. Fregni, D. Simon, C. Deblieck, and A. PascualLeone, "Noninvasive brain stimulation for Parkinson's disease and dystonia," Neurotherapeutics, vol. 5, no. 2, pp. 345-361, 2008.

[18] M. A. Nitsche, K. Fricke, U. Henschke et al., "Pharmacological modulation of cortical excitability shifts induced by transcra- nial direct current stimulation in humans," Journal of Physiology (London), vol. 553, no. 1, pp. 293-301, 2003.

[19] A. Bastani and S. Jaberzadeh, "Does anodal transcranial direct current stimulation enhance excitability of the motor cortex and motor function in healthy individuals and subjects with stroke: a systematic review and meta-analysis," Clinical Neurophysiology, vol. 123, no. 4, pp. 644-657, 2012.

[20] D. Nowak, K. Bösl, J. Podubeckà, and J. Carey, "Noninvasive brain stimulation and motor recovery after stroke," Restorative Neurology and Neuroscience, vol. 28, no. 4, pp. 531-544, 2010.

[21] A. Fusco, M. Iosa, V. Venturiero et al., "After vs. priming effects of anodal transcranial direct current stimulation on upper extremity motor recovery in patients with subacute stroke," Restorative Neurology and Neuroscience, vol. 32, no. 2, pp. 301-312, 2014.

[22] L. Tedesco Triccas, J. Burridge, A. Hughes et al., "Multiple sessions of transcranial direct current stimulation and upper extremity rehabilitation in stroke: a review and meta-analysis," Clinical Neurophysiology, vol. 127, no. 1, pp. 946-955, 2016.

[23] B. Elsner, G. Kwakkel, J. Kugler, and J. Mehrholz, “Transcranial direct current stimulation (tDCS) for improving capacity in activities and arm function after stroke: a network metaanalysis of randomised controlled trials," Journal of Neuroengineering and Rehabilitation, vol. 14, no. 1, p. 95, 2017.

[24] A. Butler, M. Shuster, E. O'Hara, K. Hurley, D. Middlebrooks, and K. Guilkey, "A meta-analysis of the efficacy of anodal transcranial direct current stimulation for upper limb motor recovery in stroke survivors," Journal of Hand Therapy, vol. 26, no. 2, pp. 162-70; quiz 171, 2013, quiz 71.

[25] J. Lüdemann-Podubecká, K. Bösl, S. Rothhardt, G. Verheyden, and D. Nowak, "Transcranial direct current stimulation for motor recovery of upper limb function after stroke," Neuroscience and Biobehavioral Reviews, vol. 47, pp. 245-259, 2014.

[26] Y. Li, J. Fan, J. Yang, C. He, and S. Li, "Effects of transcranial direct current stimulation on walking ability after stroke: a systematic review and meta-analysis," Restorative Neurology and Neuroscience, vol. 36, no. 1, pp. 59-71, 2018.

[27] D. Moher, K. F. Schulz, and D. G. Altman, "The CONSORT statement: revised recommendations for improving the quality of reports of parallel group randomized trials," BMC Medical Research Methodology, vol. 1, no. 1, p. 2, 2001.

[28] V. Sattler, B. Acket, N. Raposo et al., "Anodal tDCS combined with radial nerve stimulation promotes hand motor recovery in the acute phase after ischemic stroke," Neurorehabilitation and Neural Repair., vol. 29, no. 8, pp. 743-754, 2015.

[29] S. Hesse, A. Waldner, J. Mehrholz, C. Tomelleri, M. Pohl, and C. Werner, "Combined transcranial direct current stimulation and robot-assisted arm training in subacute stroke patients: an exploratory, randomized multicenter trial," Neurorehabilitation and Neural Repair, vol. 25, no. 9, pp. 838-846, 2011.

[30] M. K. Fleming, J. C. Rothwell, L. Sztriha, J. T. Teo, and D. J. Newham, "The effect of transcranial direct current stimulation on motor sequence learning and upper limb function after stroke," Clinical Neurophysiology, vol. 128, no. 7, pp. 13891398, 2017.

[31] L. T. Triccas, J. H. Burridge, A. Hughes, G. Verheyden, M. Desikan, and J. Rothwell, "A double-blinded randomised controlled trial exploring the effect of anodal transcranial direct current stimulation and uni-lateral robot therapy for the impaired upper limb in sub-acute and chronic stroke," 
NeuroRehabilitation, vol. 37, no. 2, pp. 181-191, 2015, Epub 2015/10/21.

[32] D. Y. Kim, J. Y. Lim, E. K. Kang et al., "Effect of transcranial direct current stimulation on motor recovery in patients with subacute stroke," American Journal of Physical Medicine \& Rehabilitation, vol. 89, no. 11, pp. 879-886, 2010.

[33] A. Fusco, F. Assenza, M. Iosa et al., "The ineffective role of cathodal tDCS in enhancing the functional motor outcomes in early phase of stroke rehabilitation: an experimental trial," BioMed Research International, vol. 2014, Article ID 547290, 9 pages, 2014.

[34] M. A. Edwardson, T. H. Lucas, J. R. Carey, and E. E. Fetz, "New modalities of brain stimulation for stroke rehabilitation," Experimental Brain Research, vol. 224, no. 3, pp. 335-358, 2013.

[35] F. C. Hummel and L. G. Cohen, "Non-invasive brain stimulation: a new strategy to improve neurorehabilitation after stroke?," The Lancet Neurology, vol. 5, no. 8, pp. 708-712, 2006.

[36] W. W. Feng, M. G. Bowden, and S. Kautz, "Review of transcranial direct current stimulation in poststroke recovery," Topics in Stroke Rehabilitation, vol. 20, no. 1, pp. 68-77, 2013.

[37] J. Marquez, P. van Vliet, P. McElduff, J. Lagopoulos, and M. Parsons, "Transcranial direct current stimulation (tDCS): does it have merit in stroke rehabilitation? A systematic review," International Journal of Stroke, vol. 10, no. 3, pp. 306-316, 2015.

[38] C. Gerloff, K. Bushara, A. Sailer et al., "Multimodal imaging of brain reorganization in motor areas of the contralesional hemisphere of well recovered patients after capsular stroke," Brain, vol. 129, no. 3, pp. 791-808, 2006.

[39] M. Lotze, J. Markert, P. Sauseng, J. Hoppe, C. Plewnia, and C. Gerloff, "The role of multiple contralesional motor areas for complex hand movements after internal capsular lesion," The Journal of Neuroscience, vol. 26, no. 22, pp. 6096-6102, 2006.

[40] G. Kwakkel, B. Kollen, and J. Twisk, "Impact of time on improvement of outcome after stroke," Stroke, vol. 37, no. 9, pp. 2348-2353, 2006.

[41] G. Verheyden, A. Nieuwboer, L. de Wit et al., "Time course of trunk, arm, leg, and functional recovery after ischemic stroke," Neurorehabilitation and Neural Repair, vol. 22, no. 2, pp. 173179, 2008.

[42] V. di Lazzaro, P. Profice, F. Pilato et al., "The level of cortical afferent inhibition in acute stroke correlates with long-term functional recovery in humans," Stroke, vol. 43, no. 1, pp. 250-252, 2012.

[43] P. Chhatbar, V. Ramakrishnan, S. Kautz, M. George, R. Adams, and W. Feng, "Transcranial direct current stimulation post-stroke upper extremity motor recovery studies exhibit a dose-response relationship," Brain Stimulation, vol. 9, no. 1, pp. 16-26, 2016.

[44] M. Nitsche, L. Cohen, E. Wassermann et al., "Transcranial direct current stimulation: state of the art 2008," Brain Stimulation, vol. 1, no. 3, pp. 206-223, 2008.

[45] A. Bastani and S. Jaberzadeh, "Differential modulation of corticospinal excitability by different current densities of anodal transcranial direct current stimulation," PLoS One, vol. 8, no. 8, article e72254, 2013.

[46] R. Lindenberg, L. L. Zhu, and G. Schlaug, "Combined central and peripheral stimulation to facilitate motor recovery after stroke: the effect of number of sessions on outcome," Neurorehabilitation and Neural Repair, vol. 26, no. 5, pp. 479-483, 2012, Epub 2012/01/20.

[47] W. Saeys, L. Vereeck, C. Lafosse, S. Truijen, F. L. Wuyts, and P. Van De Heyning, "Transcranial direct current stimulation in the recovery of postural control after stroke: a pilot study," Disability and Rehabilitation, vol. 37, no. 20, pp. 1857-1863, 2015.

[48] V. Tahtis, D. Kaski, and B. M. Seemungal, "The effect of single session bi-cephalic transcranial direct current stimulation on gait performance in sub-acute stroke: a pilot study," Restorative Neurology and Neuroscience, vol. 32, no. 4, pp. 527-532, 2014.

[49] B. W. Vines, C. Cerruti, and G. Schlaug, "Dual-hemisphere tDCS facilitates greater improvements for healthy subjects' non-dominant hand compared to uni-hemisphere stimulation," BMC Neuroscience, vol. 9, no. 1, article 1471-2202-9103, p. 103, 2008.

[50] F. Buma, G. Kwakkel, and N. Ramsey, "Understanding upper limb recovery after stroke," Restorative Neurology and Neuroscience, vol. 31, no. 6, pp. 707-722, 2013.

[51] C. Stinear and W. Byblow, "Predicting and accelerating motor recovery after stroke," Current Opinion in Neurology, vol. 27, no. 6, pp. 624-630, 2014. 


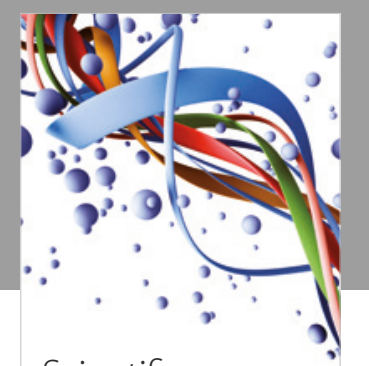

Scientifica
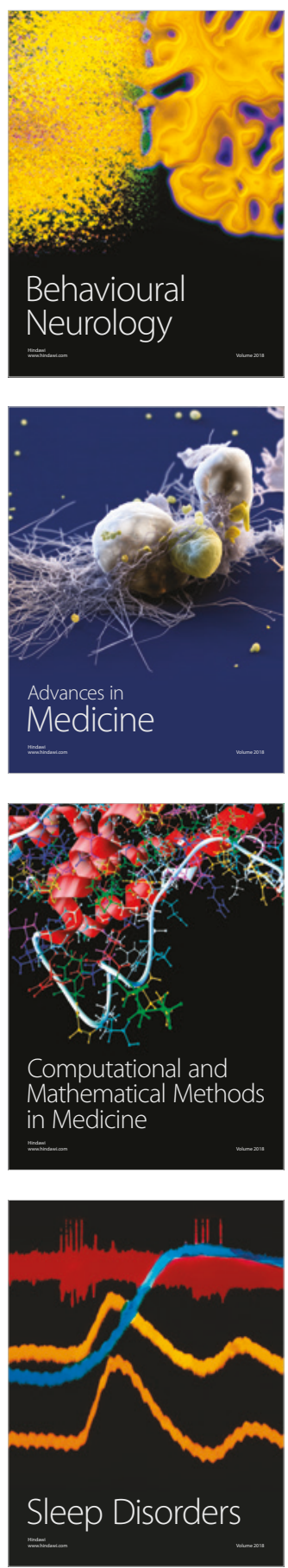

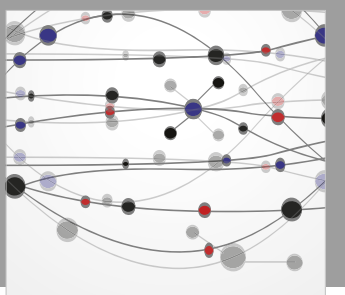

The Scientific World Journal

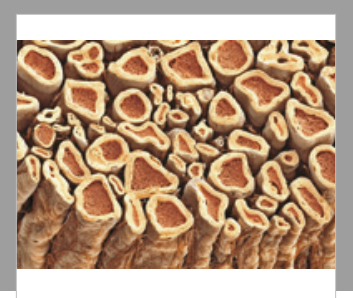

Case Reports in

Neurological Medicine

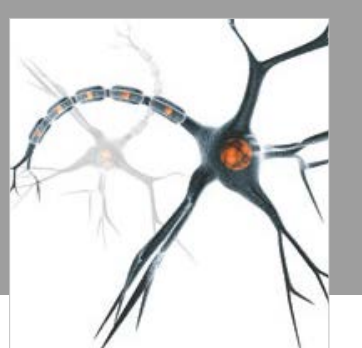

Neural Plasticity

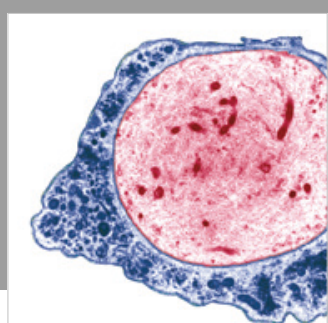

Multiple Sclerosis

International

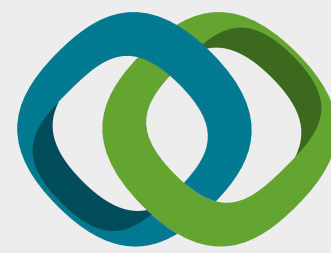

Hindawi

Submit your manuscripts at

www.hindawi.com
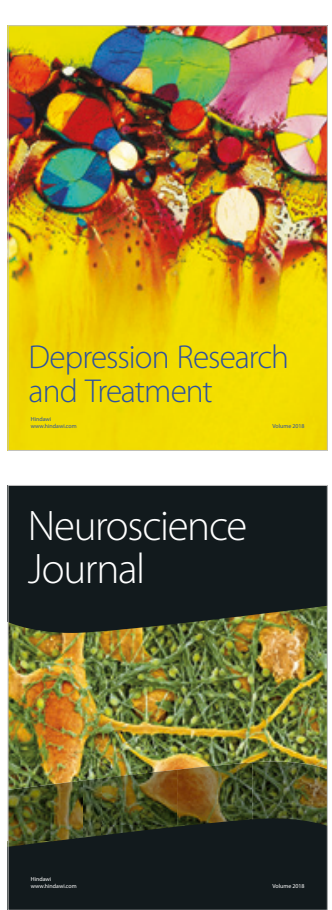

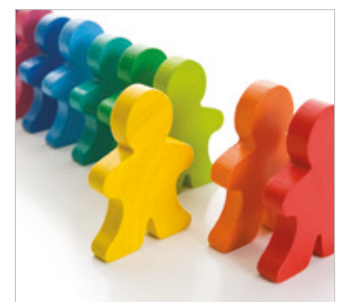

Autism

Research and Treatment
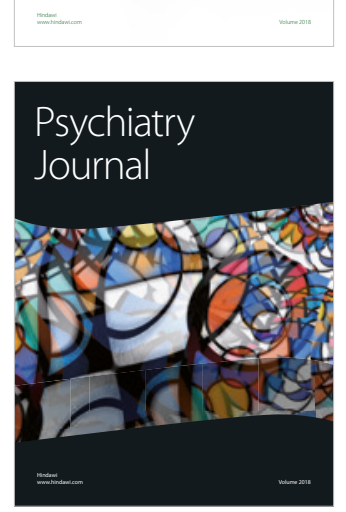
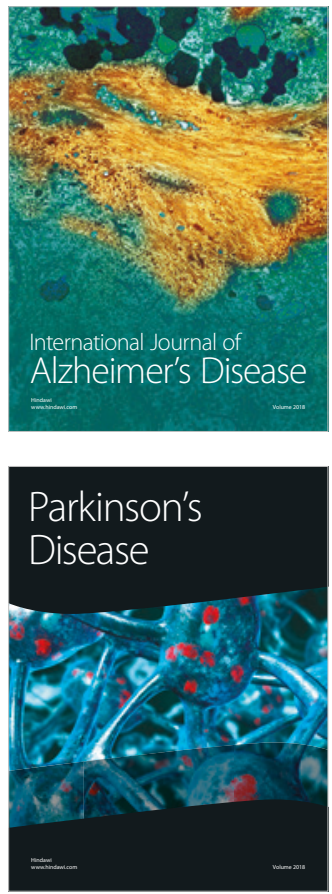
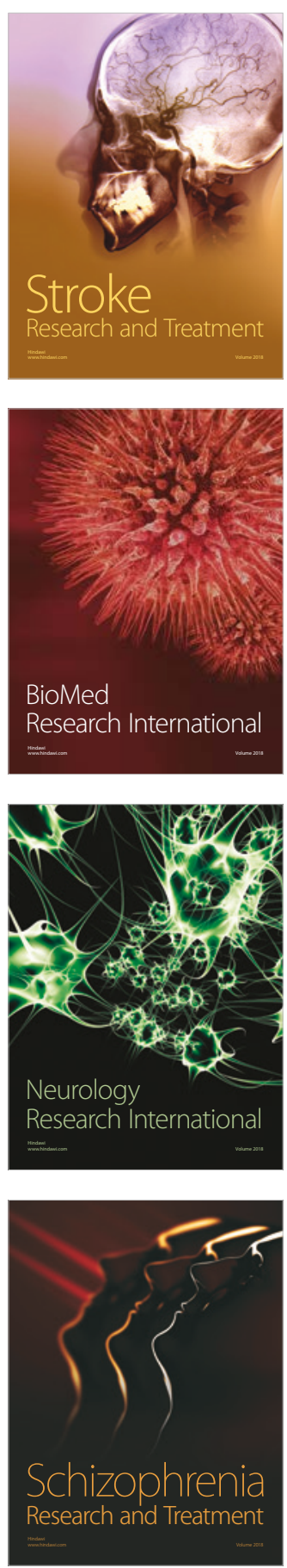